This item was submitted to Loughborough's Research Repository by the author.

Items in Figshare are protected by copyright, with all rights reserved, unless otherwise indicated.

\title{
Exploring consumers' motivations to engage in innovation through co- creation activities
}

PLEASE CITE THE PUBLISHED VERSION

https://doi.org/10.1108/EJM-12-2010-0637

PUBLISHER

(C) Emerald

VERSION

AM (Accepted Manuscript)

\section{PUBLISHER STATEMENT}

This work is made available according to the conditions of the Creative Commons Attribution-NonCommercialNoDerivatives 4.0 International (CC BY-NC-ND 4.0) licence. Full details of this licence are available at: https://creativecommons.org/licenses/by-nc-nd/4.0/

\section{LICENCE}

CC BY-NC-ND 4.0

\section{REPOSITORY RECORD}

Roberts, Deborah, Mathew Hughes, and Kia Kertbo. 2019. "Exploring Consumers' Motivations to Engage in Innovation Through Co-creation Activities”. figshare. https://hdl.handle.net/2134/26356. 


\title{
Exploring Consumers’ Motivations to Engage in Innovation Through Co-Creation Activities
}

To be cited as: Roberts, D., Hughes, M. and Kertbo, K. (2013), “Exploring Consumers’ Motivations to Engage in Innovation through Co-Creation Activities”, European Journal of Marketing, forthcoming

\begin{abstract}
Purpose - This paper explores what factors motivate consumers to engage in co-creation innovation activities. We propose that motivations differ across types of activities, whether working independently, as part of a community or directly with the firm. We offer theoretical explanations as to why this might be the case.

Design/methodology/approach - Adopting an exploratory research design, the study consists of a series of online interviews with participants in the gaming and video games industry.

Findings - Motivations appear to differ across types of co-creation efforts. Innovating independently of the firm appears to be driven by egocentric motives; innovating as part of a community appears to be driven by altruistic motives; and innovating directly in collaboration with the firm appears to be driven by opportunity- (or goal-) related motives.
\end{abstract}

Practical implications - Understanding the factors that motivate consumers to engage in co-creation activities enable firms to strategically manage their co-creation relationships and innovation processes.

Originality/value - The study shows that although motivations diverge across types of co-creation activities, a set of common motivators exist that underpin engagement regardless of the form of cocreation. However, these overarching motivators differ in how they can be successfully used towards co-creation. The study draws on theories of extrinsic and intrinsic motivation, tension-reducing, selfefficacy and expectancy theories, to explain why differences persist. This enables researchers to consider how value might be optimised across varying forms of co-creation, and build better studies into the management and performance implications of consumer value co-creation.

Keywords -Value-co-creation, Motivation, Innovation, Social exchange

Paper type - Research Paper 


\section{Exploring Consumers’ Motivations to Engage in Innovation Through Co-Creation Activities}

\section{Introduction}

The emergence of the service-dominant logic debate in marketing (Vargo and Lusch, 2004) has led to a burst of scholarly interest in consumer value co-creation. Studies have investigated its benefits for firms' innovation performance (Blazevic and Lievens, 2008); the cost, scale and competitive advantages released by consumer value co-creation (Cook, 2008); and factors shaping the intention of individuals to create products for their own consumption (Xie, Bagozzi and Troye, 2008). Conceptual treatments of consumer value co-creation have associated it with better long run consumer satisfaction and market performance (Payne, Storbacka and Frow, 2008).

A review of emerging literature shows the majority of research has focused on the nature of consumer value co-creation. What is absent in the debate is a thorough examination of why consumers engage in value co-creation activities with firms, and, in turn, what factors motivate consumers to engage in such activities. Responding to this research challenge is important because understanding what motivates consumers to engage value co-creation might enable firms to strategically manage their interactions with consumers in a way that creates superior value for the consumer (e.g., superior and better aligned products) and for the firm itself (e.g., superior wealth and growth). It also raises the possibility of investigating ways in which individuals are motivated and whether the form of motivation has an impact on creating value with the firm. In effect, the study of consumer value co-creation lacks sufficient understanding of the consumer's motivation and renders a significant gap in our knowledge of customer-centric innovation.

A handful of recent studies have shed conceptual and empirical light on consumers' intentions to participate in value co-creation processes. For example, Xie et al. (2008) show how global values held by individuals influence their domain-specific values about 'prosumption' (when buyers [co-]create goods for their own consumption), and how those values affect consumers' attitudes, self-efficacy and intentions toward ever engaging in cocreation. Payne et al. (2008) describe co-creation as a recursive process in that co-creation opportunities induce a consumer learning experience that can motivate further co-creation activities and improve co-creation outcomes. At the heart of this process are consumer emotion, cognition and behaviour in relation to co-creation opportunity. Other studies reveal the role emotions play in stimulating consumer involvement in the co-creation of valuable 
innovations (Füller, Matzler and Hoppe, 2008), as well as the product-service, community and medium-related benefits that consumers realize by participating in new product development (Nambisan, 2002).

Despite these studies, an unusual anomaly persists: consumers' motivations to engage in co-creation processes are aggregated in such a way that no differences are anticipated, whether they are innovating directly, contributing to the innovation activities of firms or choosing to enter into collaborations with firms in the first place. Only Jawecki (2008) has made an attempt to disaggregate consumers' motives, reporting differences across three types of activities: motives to innovate individually, motives to contribute to innovation activities, and motives to collaborate with firms. However, the study limits its view of motivation to need and excitement and lacks a unifying frame of reference. It tells us that motives differ by activity across areas of co-creation but not why they do so.

Our study attempts to address these gaps in our knowledge of consumer value cocreation as part of a product innovation process. Two research questions are answered. The first is to what extent, and on what basis, do consumer motivations differ across types of cocreation (independent innovating, joint innovation activities, and direct collaboration with a firm) and what consistent motivating factors exist across these types? Second, along what theoretical dimensions can these motivating factors be reconciled to provide a unifying framework of consumer motivation that engages in value co-creation?

Three important contributions to marketing and innovation theory surrounding consumer value co-creation are offered. First, the study explains that although motivations diverge across types of co-creation activities, a set of common motivators exists that underpin engagement regardless of the form of co-creation. These overarching motivators simply differ in how they can be successfully leveraged for different forms of co-creation. This information enables researchers to construct more fine-grained models of a consumer-centric innovation process. Second, the study draws on theories of extrinsic and intrinsic motivation (Deci and Ryan, 1985), tension-reducing theory (Lewin, 1951), self-efficacy (Bandura, 1977), and expectancy theory (Vroom, 1964) to explain why differences persist. Third, we synthesize and reconcile these diverse theoretical lenses with Holbrook’s (2006) model of consumer value to show the complexities of engaging consumer motivation in the value co-creation process. Our work enables researchers to reconsider how value might be optimised across different forms of co-creation and then build better studies into the performance implications of consumer value co-creation. 


\section{Theory}

\subsection{Consumer value co-creation}

Consumer value co-creation is defined as collaborative work between a consumer and a firm in an innovation process, whereby the consumer and supplier engage (to varying degrees) in the activity of co-ideation, co-design, co-development and co-creation of new products or services (Prahalad and Ramaswamy, 2004). In part, co-creation is a specific form of user contribution whereby 'active' as opposed to 'passive' consumers participate with the firm and voluntarily contribute input (be that knowledge, informed opinions, experience or resources) into an innovation process (Cook, 2008), whose outcome is better and more market-focused innovation.

Value co-creation, however, should not be confused with value co-production. Etgar (2008) draws on the work of Lusch and Vargo (2006a, b) to define the differences between co-creation and co-production and to define at what stage of a product's life a consumer participates in the two forms of value co-development. Our work focuses on co-creation, not co-production, though these elements can overlap in that "consumption activities are not separate from co-production activities but connected to them” (Etgar, 2008, p.97). Such a proposition is beyond the scope of this paper. Etgar (2008) and Lusch and Vargo (2006a, b) define the co-creation of value as taking place in the consumption stage (i.e., when the consumer is using or consuming the product following production and launch), and coproduction as taking place in the production process preceding the consumption stage (i.e., during the development of the initial product). This distinction is important because the subjects of our study interact with a product that has already been launched and thus cocreate value at the usage/consumption stage.

In industries where new IP is considered important, many product launches are shrouded in secrecy to prevent competitor imitation and to reduce the scope for rapid competitor response, imitation or pre-emption of the new IP/product. In such instances, codevelopment of value generally takes place in the usage/consumption (i.e., post production and launch) stage, where individuals can be motivated to explore new possibilities with the IP/product, or be motivated to work with others in these efforts. Such collaboration can cocreate value by way of a revised or improved IP or product, and could lead to consumers being co-opted in to inform a sequel IP/product if their efforts prove worthwhile.

An ideal illustration of this situation is the 'gaming' or 'video games' industry in which the secrecy of new IP/products is paramount and the co-development of value can only take place when a supplier adds knowledge, tools and capabilities to the customer's pool of 
resources (e.g., Payne et al., 2008). It is not possible for consumers in this industry to readily co-produce value because a game/software must be launched before consumers can exert individual innovation or joint/community innovation efforts that co-develop improvements to the product. Doing so requires that developer or 'engine' tools be made available by whoever owns the 'engine' and the IP. It follows that in terms of a current game or software product, co-creation of value is taking place and co-production is scarce.

Jawecki (2008) helps us anticipate three types of co-creation activities in which innovation outputs are likely to coalesce around revisions, improvements and enhancements to a product post launch: independent innovating, joint innovation activities, and direct collaboration with a firm. These activities are not industry or sector specific and are not necessarily sequential although an individual might move from one activity to another or perform more than one simultaneously. These are designed to add incremental, additional, revised, new or improved features or content that were absent from the original product, improving its appeal and value proposition. Deploying the consumer as a co-creator of value then utilises the consumer as an operant resource in the firm's innovation process (Xie et al., 2008), making use of his skills, knowledge and creativity. Accordingly, the value of a product or service is crystallised and improved much earlier than had the creation of value been left solely to the firm, thereby enhancing marketplace acceptance and product longevity (Shah, 2006).

\subsection{Consumers’ motivations to co-create value}

'Motivation' can be thought of as the antecedent condition that compels human behaviour (of some form) to occur. Motivation explains why people behave in certain ways, what energises their behaviour and what directs their subsequent voluntary action(s) (Deci and Ryan, 1985; Nambisan, 2002). Extant research posits that the quality of consumer contribution to a firm's innovation activity is likely to depend on his perceptions of the tangible or intangible ‘benefits’ accruable from it (Nambisan, 2002). Studies then should seek to determine the benefits motivating or driving consumers to participate in different forms of co-creation activities. The notion of 'benefit' can be thought of as a broader depiction of 'customer value', although it tends to distil the study of motivation to economic terms (Holbrook, 2006) when broader views of motivation should focus on the reasons that underpin a decision to act in a specific way.

Customer value can take different forms. Holbrook (2006) asserts a typology of customer value that is self-/other-oriented and extrinsic/intrinsic in nature and which 
proposes economic (self-extrinsic), social (other-extrinsic), hedonic (self-intrinsic) and altruistic (other-intrinsic) forms of value for any given consumer product, service or activity. While it is commonly understood that motivation can also take extrinsic and intrinsic forms, it is necessary to distinguish between 'consumer value' and 'motivation'. Holbrook (2006) specifies that the value of a product, service or activity to a consumer is dependent on his object-subject interaction within a particular situation. Motivation, on the other hand, spurs that interaction and stems in part from the 'satisfying experiences' achieved through such interactions (Abbott, 1955).

We anticipate that motivations will likely differ across the three types of co-creation activities (independent innovating, joint innovation activities, and direct collaboration with a firm), because benefits sought are unlikely to remain the same across those activities. Considering varying forms of consumer value co-creation is important because the context and extent of engagement with a firm or community differ in each case, and consumer motivation is impacted in direct relationship to the potential for 'value' or a 'satisfying experience' (Abbott, 1955; Holbrook, 2006). For example, innovating on a firm’s product independent of the firm itself suggests that entirely self-centred reasons are at play. Research associates such behaviour with an internal need to achieve a more satisfactory product and a sense of fun and excitement from the creative act of product modification (Franke and Shah, 2003). In Holbrookian terms, these might be thought of as aspects of economic or hedonic value. On the other hand, engaging with a community of consumers to contribute to joint innovation activities is likely to differ owing to the social interaction that characterises such work. The creation of new or modified products then represents a joint effort brought about by the coalescence of knowledge, skills and activities from multiple consumers operating through a pattern of social exchange. In such cases, research associates motivation with reputational gains, opportunities for recognition and network effects such as building community ties, being valued by others, belongingness, friend-making and reciprocal learning (Harhoff, Henkel and von Hippel, 2003; Jawecki, 2008; Shah, 2006). Such motivations correlate with Holbrook's (2006) notion of social and altruistic value. It should be noted that some motives might overlap co-creation activities but differ in nature. For example, participation in joint innovation activities has also been associated with a sense of passion, fun and excitement (Franke and Shah, 2003; Jawecki, 2008). But, a sense of fun and excitement when innovating independently on a firm's product is located solely in the self, whereas fun and excitement derived from engaging in joint or community innovation are grounded in social interaction, rendering such motives entirely different in nature. 
Nevertheless, these insights are limited as they do not directly map ways in which a firm could leverage such motivations to engage consumers in a closer form of co-creation.

A discussion of motives across the three types of consumer value co-creation would be incomplete without a review of interweaving motivation theories. This effort may shed more light on the dynamics of motivation that shape consumers' engagement in value cocreation and provide firms with levers to aid in better engaging consumers in co-creation activities.

\subsection{Consumers' motivations to innovate: Goal-based theory and personal intrinsic motivation}

Consumer motivation to innovate on a product without any material engagement with the firm is likely to be triggered by some form of personal need or dissatisfaction with the product as it stands (Franke and Shah, 2003; Lewin, 1951) or the experience it currently provides (Holbrook, 2006). When an individual develops ‘disequilibrium' at the psychological level, this disequilibrium will energise behaviour until equilibrium is restored (Deci, 1992; Evans, Jamal and Foxall, 2006). Achieving equilibrium (or satisfaction) places the individual into a state of 'homeostasis' in which action stops as the drive no longer exists (Evans et al., 2006). This view is an extension of classic drive theory except that drivers are psychogenic, or cognitive, and not physiological. The presence of cognitive dissatisfaction with the product is an incomplete explanation for the motivation to innovate though. Instead, expectancy theory (Vroom, 1964) suggests that behaviour is influenced by expectations of achieving desirable outcomes. The concept of desired outcomes, or a desired equilibrium state, is captured in goal-based theory.

In goal-based theory, cognitive processes lead individuals toward accomplishing goals. These cognitive processes are tension-based and tension emerges when a consumer's present and idealised state, relative to a product or service, differ (Lewin, 1951). A consumer then creates a 'goal', representing a 'desired future state', which drives tension-reducing behaviour (Deci, 1992); that is, the individual will seek to innovate and improve the product or service. However, the consumer's motivations to innovate are still predicated on some form of dissatisfaction with the firm's products or services. Expectancy theory and the related control-of-reinforcement theory offer a further basis on which to clarify a consumer's motivation to innovate, and the role of the firm therein (Bandura, 1977; Deci, 1992; Vroom, 1964). 
Bandura (1977) posits that a consumer's motivation stems from the expectation that his or her action will lead to the desired reinforcement of a favoured situation, result or outcome. Reinforcement of what the consumer 'values' captures the motive but the extent of action is dictated by the expectancy that desired outcomes can and will follow. It is at this point that firms can leverage such motives to provoke value co-creation. We propose that these motives are personal intrinsic needs, or specific internal psychological needs, that have hedonic value like competence and self-development or the sense of fun and excitement derived from achieving a goal (Füller, 2006). These needs typically capture egocentric goals like pursuing personal growth and development, experiencing stimulating challenges and accomplishing goals (Csikszentmihalyi, 1991). They operate as motivators and fulfil in individuals the need to feel competent and in control of their achievements (Deci and Ryan, 1985). A sense of, and improvement in, competence captures the individual's self-efficacy at performing a behaviour underpinning a goal (Bandura, 1977). Nevertheless, to motivate consumers to innovate independently, firms need to make tools available for consumers to use. These tools can consist of supplying information about the product's architecture or, in the case of the software industry, supplying items such as open-source coding software and developer tools that enable individuals to take action.

Tying these assertions together, one can expect that dissatisfaction with a product and the resulting desire for better features and functions might motivate consumers to begin innovating (Deci, 1992). Working on dynamic and complex tasks (such as innovating on a firm's product) creates opportunities to learn and increase competence that should motivate consumers to innovate (Wikstrom, 1996), and the challenge of achieving such innovation generates fun and excitement (Füller, Bartl, Ernst and Muhlbacher, 2006; Franke and Shah, 2003) that fuels the ego and develops the skills of the individual (Bandura, 1977).

\subsection{Consumers' motivations to contribute to joint (or community) innovation activities:} social exchange theory, extrinsic motivation and relational intrinsic motivation.

A consumer's motivation to contribute to joint innovation activities at a community level requires a shift from individual, ego-centred motivation to one that embraces the social setting the individual is entering. If we accept that the motivation to contribute to joint innovation initiatives is based on the expectation of achievable rewards, then in a social setting where a consumer is co-creating with peers, the rewards become bound in the social exchange that takes place (Füller, 2006; Wikstrom, 1996). Social exchange theory is based on a subjective process of cost-benefit evaluation in which an individual engages to determine 
the benefits he or she is likely to gain from entering into a relationship or set of ties (Wikstrom, 1996). Participation is contingent upon whether the perceived benefit is achievable with reasonable expended effort (Füller, 2006). Thus, an interaction has to be rewarding to each participant in the social exchange (Bagozzi, 1975; Füller et al., 2006), and cannot be led by egocentric drivers or the social exchange will likely break down. Motivators of innovation activities are then more likely to be social and altruistic in nature (Kollock, 1999), centred on soft extrinsic drivers and relational intrinsic motivators.

Classical views of extrinsic motivation associate extrinsic needs with external incentives that are separate from the activity per se, and are typically thought of as utilitarian in nature based on some functional or practical benefit (Daugherty, Eastin and Bright, 2008). But this view is insufficient in explaining consumer value co-creation through joint innovation activities with a community of peers. The outcome of social exchange relies on trust, which forms when individuals' motivations are in some sense aligned with and reciprocal to others. In the context of social exchange, expectations of reciprocity (Franke and Shah, 2003), the receipt of feedback on innovations and innovative ideas, developing strong ties within a community, ‘feeling like part of a family’ (Mathwick et al., 2007), and becoming privy to new information about the product in question (Butler, Sproull, Kiesler and Kraut, 2002), have been reported as extrinsic motivators.

The results of several studies into consumer co-creation appear to underestimate the role of social mechanisms in motivating consumer value co-creation. For example, in Etgar's study of co-production (2008), he posits that engaging in co-production of innovation can provide consumers with status and social esteem rewards that consolidate their position among peers. We conclude that participation in activity networks of the kind that connects a creator with his or her peers, results in social contact values that are common to the members, and that these individuals share in the altruistic value of undertaking meaningful activities with people of similar interests, desires, knowledge and skills (Holbrook, 2006). Over time, they share in the opportunity to form co-creation communities and social co-creation networks which shape into an unusual sense of belongingness, identity and bonding among individuals (Achrol and Kotler, 2006). It is at this point that initial extrinsic needs give way to intrinsic relational needs.

Intrinsic motives that are relational in nature have their roots in social exchange. For example, a group of like-minded individuals that share common interests more naturally form opportunities for friendship, develop belongingness and identity, attain a level of social status and obtain feedback and recognition from ‘critical friends’ (Kozinets, 2002; Nambisian, 
2002). The process of social interaction that develops also generates reputational effects and a sense of wellbeing that flows from being valued by peers and from contributing to the work of others in this community (Holbrook, 2006). As Kollock (1999) proposes, at a community level, the motivations of individuals tend toward altruistic values and it is for this reason that community members freely share their innovative ideas and content with others in a way that facilitates and leverages value co-creation. Nevertheless, altruistic values can only generate these outcomes over time when community members appreciate their mutual obligations. As interactions among members increase, social relationships create trust and intensify the credibility of the information the group exchanges (Butler et al., 2002). Coupled with a greater sense of belonging and shared expectations, obligation for reciprocal exchange will likely increase, thereby paving the way for more meaningful innovation outcomes (Butler et al., 2002).

These arguments are consistent with research into relational embeddedness, in which greater embeddedness in a network of relationships increases idiosyncratic access to knowledge but also increases the reciprocity among members to sustain trust, which generates more valuable outcomes among members (Granovetter, 1985). It would then be expected that consumers' motivations to contribute to joint innovation activities are driven by social and altruistic motives. This requires a different organisational approach than the one used to engender individual co-creation. The tangible return is a superior product encompassing the joint, not singular, interests of the community. Simply put, peer dynamics temper self-centred motives in favour of those based on social exchange.

\subsection{Consumers' motivations to innovate collaboratively directly with firms: expectancy} theory and consumer involvement

Motivating consumers to collaborate directly with firms requires co-creation activity evolving into its purest form, more closely correlating with how absolute value co-creation between a consumer and a firm might be defined. Still, the underpinning principle for engagement is similar: expectancy. Under the principles of expectancy theory (Vroom, 1964; Vroom and Jago, 1978), the consumer must expect a benefit prior to collaborating with a firm on a value co-creation initiative and believe the benefit is achievable. It is in the latter part of this equation that we can expect to see challenges.

Motivation to work with firms is likely to be opportunity-based due to the novel prospect for consumers to directly inform products, ensuring products that reach the market are better aligned with their interests, and if profitable, shape possible career opportunities 
within the firm or industry (Füller, 2006). It follows that this collaboration achieves economic value for the consumer and social value from the esteem such activity confers (Holbrook, 2006). The difference in expectancy versus other forms of co-creation is that the emergence of an innovation and achievement of the consumer's desired reward depends on an organisation the consumer cannot control. Consumers with internal loci of control are likely to be less affected in this instance than those with external ones (Rotter, 1966) because such consumers will directly attribute their ability to succeed to their own capabilities. Moreover, action depends on the consumer's perceived self-efficacy and is characterised by the strength of the individual's belief that he possesses the competence to achieve the desired outcome (Bandura, 1977). The firm can directly affect this belief by creating a state in which performance can lead to the desired outcome by supporting the competence of the individual (e.g., the firm provides the individual with resources and support that engage him in cocreation. The firm then makes use of the input in at least the innovation process, if not in the end innovation output).

The danger for the firm in this situation is to miscalculate the individual's motivation. Known as goal-gradient hypothesis (Kivetz, Urminsky and Zheng, 2006), the individual will likely expend more effort as he approaches the goal and its rewards. A consumer demonstrating the tendency to accelerate toward a goal attains greater and faster reengagement in a firm's programme (Kivetz et al., 2006). Extending this hypothesis to value co-creation, a consumer's initial motivation may change as his self-efficacy develops and as the end result is unveiled. Expectancy theory offers that the amount of effort the consumer expends correlates directly with the expectation that a desired goal will be achieved (e.g., innovation) and will lead to certain consumer-valued outcomes (e.g., better product, firm prospects) (Vroom and Jago, 1978). Succinctly stated, when instrumentality (likelihood of outcome resulting from goal achievement) and valence (actual value of the outcome to the individual) are high, the consumer will be motivated to initiate and complete the co-creation activity (Vroom and Jago, 1978), as long as the goal is achievable (Kivetz et al., 2006) and within the competence of the individual (Bandura, 1977). Consumer motivation then directly depends on the firm's management of the co-creation process.

In summary, the review of theories relevant to the debate on motivation, consumer involvement and value co-creation, discloses that differences exist and persist across each form of value creation. We assert that consumer motivation to innovate on a product independent of the firm is driven by a desire for a better product and to improve personal skills and competencies. We assert that consumer motivation to contribute to the innovation 
co-creation efforts of a community of users is driven by social exchange and the individual's intrinsic relational need for acceptance, recognition and respect from important peers. And last, we assert that consumer motivation to co-create directly with the firm is driven by the expectancy that outcomes valuable and meaningful to the individual and other parties will result. Figure 1 captures our re-construction of Holbrook’s (2006) typology of consumer value using theoretical observations from the literature on motivation. This framework illustrates that the motivation to pursue value co-creation activity does not separate cleanly in the manner implied by Holbrook's (2006) typology, but rather that motivation underpinning value can be quite different from the form of value, creating variance in the consumer's voluntary choice to engage in co-creation activities.

(Insert Figure 1)

\section{Methodology}

The literature review highlighted the necessity to better understand consumers' motivations for engaging in different forms of co-creation. Given that human beings are complex in nature, with attitudes and values led by diverse motivators, a qualitative and interpretivist approach was used to collect and analyse data. This method acknowledges the unique natures of individuals and allows subjective data to be revealed and analysed.

While the adoption of value co-creation in consumer markets is in its infancy compared to service and industrial markets, the Internet has been identified as a useful platform on which consumer co-creation relationships can be developed (Szmigin, Canning and Reppel, 2005). Accordingly, the interactive entertainment and online gaming industry was selected as appropriate context for our research. Highly profitable and predicted to grow from \$74bn in 2011 to \$115bn by 2013 (Hinkle, 2011), online communities set up by fans/gamers and game publishers have flourished, giving the gaming company access to the vast pool of knowledge and innovative capabilities of their consumers. Users engage in producing content by sharing with other users and the gaming company itself their ideas about and experiences with the games they play and how they might be improved.

We adopted an interactive online approach to data collection. As advocated by Kozinets (2002), prior to initiating contact with potential participants, the researchers developed an understanding of the idiosyncrasies of leading online gaming communities Civilization IV and Electronic Arts. The moderators/administrators of the selected gaming communities were then contacted through personal messaging. Bryman and Bell (2003) stress the importance of this approach as unsolicited posts/email may be considered a nuisance. 
Ethical issues can also be addressed and informed participation and voluntary consent obtained. Further, when the context of the research is outlined in the introductory post it reveals information about the researchers and can lead to the receipt of a greater number of responses (Curasi, 2001).

Once initial contact was made with the communities, purposive sampling was used to select respondents, thereby sampling for theory building, not representation. In-depth interviews were conducted with 17 people in an online gaming community. Of the 17 participants, 14 were males and 3 were females and the mean age of the participants was 27 . Semi-structured interviews were conducted using a topic guide, but were not constricted in their frame of reference so the researchers had the freedom to probe for clarification and confirmation (Bryman and Bell, 2003). This enabled new insights and refinements to existing theory. The participants chose between 'asynchronous’ online interviews where they conducted a discussion in their own time and 'synchronous' interviews with the researchers (Curasi, 2001). Probing techniques through a process similar to laddering was used to further reveal participant motives and values (Gephart, 2004).

Our data analysis methodology follows advice by Kozinets (2002) and Pratt (2009) among others. Interview data was analysed by coding and grouping and then analysing the coded groups (Miles and Huberman, 1994). This process was aided by iteratively clustering and organising the data according to key words and a list of motives drawn from the literature review. This system of coding was used to break the rich textual data into component parts. This method unveils the patterns, common themes and constructs that emerge from the data, while enabling us to better understand the interaction between the data and existing theory (Miles and Huberman, 1994). Coding and preliminary analysis can be found in Table 1. Following Pratt (2009), selective quotes are used to illustrate our findings. The technique of alternating the discussion between 'telling' and 'showing' theoretical elements and quotes/excerpts from the interviews is advocated by Locke (2001) as a means to powerfully yet concisely present interview findings.

(Insert Table 1)

\section{Findings}

Our findings are conceptualised in Figure 2 and organised around individuals' motivations to innovate, motivations to contribute to community innovation activities and motivations to 
collaborate directly with companies. ${ }^{[1]}$ The model provides a visual representation of the findings, illustrated with excerpts from interview transcripts (Pratt, 2009).

(Insert Figure 2)

It was apparent from the interviews that individuals who participate in online gaming communities develop innovation-related ideas and content by themselves and in collaboration with other community users. Firm involvement in these co-creation activities is indirect but no less significant since the firm must provide tools and resources that enable consumers to innovate. Users develop ideas and game-related content, share these ideas with other community members, give each other feedback, discuss ways to improve the game, and sometimes relay this information to the gaming publisher. Virtually every kind of idea or user-generated content related to games is conceived, created, and shared; these may include anything from how to improve certain game features or functions, including the artificial intelligence of the game, to actually designing new game interfaces, characters and maps. User-generated game content does not necessarily have to be integrated into the game's features but can include such things as artwork, which the creators then share with the community. Valuable and highly original creations can also act as promotional material for the game. These activities present a treasure trove for organisations who seek to identify and incorporate consumer needs and wants into their products.

\subsection{Motivations to Innovate}

Gamers are usually immersed in the virtual reality of the game and they require positive experiences to feel enjoyment. When gamers are passionate about a game but feel it can be improved, they can become stimulated to design user-generated content with the goal of improving their gaming experience. The act of designing content was widely regarded as being fun or exciting to the interviewees as it served as a creative outlet toward realizing their desires for better gaming experiences. The longing for a better product or gaming experience was frequently cited as motivation for engaging in individual innovative activity. The following passages identify the need for the process to be both fun and challenging.

"There is something satisfying about completing a mod and knowing you have taught the game something new. [...] Beyond that it all comes down to fun, no one pays us to mod, so if it's not fun I'm moving on to the next project that provides me enjoyment. So I guess you 
could say I create content so I can play the game with it, but the first rule is I have to have fun creating it or it's not going to happen."

(Jeckel)

"I want to help improve the gaming experience"

(Mathrodi)

"By nature I am a creative person so if I create a new idea or content I derive joy from that. I just like to be creative, so if I want to create an intricate house for example, that process is fun for me. Finding the right doors, furniture, landscaping (the whole bit) is just something that I really enjoy. Maybe it is because I don't have the ability to do this in real life that makes it fun.

(Djcleopatra)

The process of innovating at the individual level was not only regarded as fun but many saw it as a hedonic way to 'kill some time', or 'forget about the worries of everyday life', and engage in something enjoyable and positively stimulating. Gamers also saw the opportunity to innovate as a challenge and means to further develop their skills. By working with different software/tools they are able to refine their programming or creative skills. The following quotation illustrates the importance to gamers of learning and skill development:

"Sometimes it can be challenging (3D Graphics), but other times it can be really fun and interesting. [...] Challenging is a positive word for me. I feel pride and accomplishment when I complete something that is deemed a "Challenge". I benefit because I have learned a new skill, and I become confident in my abilities."

(Djcleopatra)

The gamers' motivation to develop new skills and competencies combined with the passion and fun they experience leads to the conclusion that motives at this level are egocentric, as shown in Figure 2. Based on Holbrook's conceptualization of customer value, while hedonic value appears to be gleaned, personal intrinsic motivation goes beyond hedonic value to achieve the 'fun' and 'fantasy' aspects of Holbrook’s (2006) conceptualization of motives that underpin the desire to acquire such value. Personal development forms an important aspect of motivation that encourages consumers to engage 
in this form of value co-creation. While not ostensibly economic in nature, it appears that it is oriented toward self-enrichment in a manner consistent with goal-based theory. These motives do not seem to stem from any cognitive dissatisfaction with the product-service (cf. Deci, 1992), but rather from the challenge of improving what many previous experts found acceptable in the product-service. This view is consistent with the notion that consumers seek ‘satisfying experiences', not product-services (Abbott, 1955), which explains their motivations to make the games better. Of note in this context are the components of consumer motivation that relate to the development of personal skills and competencies as precursors to improving individual self-efficacy at value co-creation, which can then lead to other forms of value co-creation, such as those at the community level or in direct engagement with an organisation. While our data does not demonstrate this potential chain causally, it remains that firms might need to make tools and resources available to consumers that are necessary for their experimentations with products-services before developing richer co-creation relationships with them. Succinctly put, despite the lack of direct involvement by the organisation in such innovation, it appears that at the very least it has an indirect influence on supporting or sparking the co-creation activity.

\subsection{Motivations to contribute to community innovation activities}

Gamers indicated the importance of sharing user-generated content and ideas for innovative new product development. They enjoyed praising and critiquing each other's contributions, and assisting each other in developing ideas or new game content. Here, a sense of fun and passion manifested in more social and altruistic ways than when innovating alone. The motivation to innovate in a community centred on the social exchange process and was hence more altruistic in nature. The following statements highlight the importance to gamers during the innovation process of developing friendships and achieving a sense of belonging:

"I want to make friends and discuss the game with like-minded people. I believe that being in a community makes the game more fun, if when you finished your session playing you can go and discuss what you like, how it could be improved, and most importantly, make friends. I also like critical commentary/analysis about a new idea, and possibly to build up support. To suggest ideas, to get feedback on my ideas. I like been told how good/bad my ideas are." 
The social interaction I seek is usually making new friend that have shared interests as myself. [...] When I have been a member a while and I have gotten to know the others and like them, then I definitely feel a sense of playfulness.

(Djcleopatra)

Once social bonds formed with other gamers in the community a sense of belonging began to take shape and users began to feel obliged to help each other for the sake of strengthening the community. Additionally, the gamers' needs to be recognised for their skills and appreciated for their contributions were motivators. For example:

"The urge to share expertise comes to mind. When you have a little knowledge on the subject, you would want to share it with others to not only help others, but improve your own skills as well. When I see that I actually have some understanding of the subject matter at hand, I would like to put in my two cents and see how my opinion weighs against others. Even then, I can still learn a thing or two from others offering their expertise on the matter at hand. Not only would I like to be considered helpful, but I just want to learn as much as anyone else. I want to have some fun."

(Mathrodi)

As expected from our initial theoretical discussion and motivation literature review, it is not surprising that a consumer's motivation to contribute to community-level innovation or value co-creation activity is defined by social exchange. Social and altruistic motives capture the reasons why individuals engage in such co-creation activities. However, while Holbrook (2006) sought to differentiate between the social and altruistic values that a consumer might derive from experiencing or interacting with a product-service, we find that at least in terms of motivation, social and altruistic endeavours are both largely indistinguishable and operate concurrently. The social experience that results inextricably interweaves the shaping of the responses of others (social) with concern for how their behaviours might affect those in the community (altruistic). Indeed, if these motives are misaligned, it is likely that the community would dissipate because the basis for trust and reciprocity would no longer exist. Thus, while the rewards of this form of co-creation appear to be bound in the social exchange that takes place (Füller, 2006; Wikstrom, 1996), the maintenance of this exchange is essential in motivating a consumer to persist over time with the co-creation effort. The relational embeddedness that ensues after such activity is perpetuated shapes the necessary trust that 
unlocks social and altruistic forms of value. In our study, co-creation activities also yielded intellectual benefits in terms of knowledge and skills development, but it was apparent from our interviews that these were not motives for engagement as much as they were welcome side-effects.

\subsection{Motivations to collaborate with firms}

The last category in Figure 2 is the motivation to collaborate directly with firms. In this stage the most commonly occurring responses were the desire for better products and the need to influence the firm's new product development agenda. For example:

"I get involved with companies, partially because I like the idea of being able to affect the product (make the game actually better), and partially because it's nice to meet people behind the game and know that real people exist in these companies."

(Snoopy369)

"Firaxis in particular seems to listen to the community. If I want something changed/added then I will mention it, as it will improve the game from my point of view."

(Blaupanzer)

Some gamers revealed their desires to pursue careers in the gaming industry and were driven to engage with gaming publishers in exchange for recognition of their talents and potential achievement of their career goals:

"I want to be a game developer in the future and I hope that by sharing my ideas it might open up career opportunities for me if they like my work."

The motives underpinning this form of value co-creation appear to be largely economic. They are not financial in nature but rather opportunity and goal based. Direct collaboration with a firm yields a unique opportunity to influence product development and raise awareness of the consumer's own ideas, skills and knowledge. From several comments made by respondents (see also Table 1) at this stage, it is clear they believe in their own selfefficacy and firms should carefully consider leveraging this confidence to build closer collaborations across other forms of value co-creation. What is unique about this context, 
however, is that co-creation output is dependent upon the firm itself. This issue was summarised neatly by two of our respondents:

"I really try it so that they can incorporate some of the ideas into the game. Most of the best ideas come from the players and they don't listen. Half of the ideas they don't take into action so we really must try our best to persuade them with the best ideas possible."

(Simmy 135)

"Yes, I think people who have open dialog with publishers are more open to sharing and exchanging information... Creators like myself like to feel a part of the project and if a developer or publisher acknowledges us we feel pretty good about that."

(Djcleopatra)

Co-creation is a two-way progression but in this instance the firm has direct influence over consumer motivation because its relative degree of interest in, collaboration with and attention to the consumer appears to influence not only the consumer's effort but also his perception of the extent to which his ideas are taken into consideration (and so the 'value' the consumer derives). Extending the goal-gradient hypothesis then (Kivetz et al., 2006), we suggest that the effort expended by a consumer in this form of value-creation is not solely dependent upon the extent to which the opportunity or goal is within sight but also upon the perceived commitment of the collaborating firm. These observations highlight a limitation in the application of traditional motivation theories because a consumer's motivation to cocreate value by collaborating directly with a firm is strongly influenced by the firm as an agent.

\section{Discussion and Conclusions}

Our results indicate that motivations differ across various forms of consumer valueco-creation so it is inadequate to forge a general study of consumers' motivation to engage in co-creation activities. In particular, it seems consumers' motivations to engage in innovation activities at an independent level are egocentric in nature and primarily based on the hedonic desire for a better product and to develop the consumer's own personal competencies and skills. Conversely, consumers' motivations to contribute to innovation activities at a community level appear altruistic in nature, shaped by social exchange and informed by relational intrinsic needs. Further, consumers' motivations to engage directly with firms in a 
full co-creation programme seem informed by longer-term opportunities and personal economic goals. Our first contribution then is to reveal not only that differences exist but explain why they do, drawing on the rich tapestry of motivation theory.

Our findings indicate that the motivation to innovate independently on a firm's products is informed by tension-based goal theory and the personal intrinsic motivation associated with setting personal goals that might be achieved as part of the co-creation effort. However, the extent to which the individual engages in a co-creation endeavour depends upon his self-efficacy in initiating the process with his own skills and competencies. A key personal motivator is the potential to develop even greater skills and competencies through this innovation attempt. The three theories coalesce to explain how 'dissatisfaction' with a product, coupled with the individual's self-belief that he can initiate change, develop into self-reinforcement as the individual generates new personal skills and competencies that over time improve the product. As a result, consumer passion and fun appear to be entirely selfcentred and motivation is egocentrically informed. The term 'dissatisfaction' is used loosely here to capture the notion that a good product-service can be made even better. While the latter is somewhat inconsistent with the traditional view of cognitive dissatisfaction, it follows the notion of an idealised future state (Deci, 1992), and is consistent with the evidence that motives in this instance appear to be in nature hedonic and personally intrinsic.

A consumer's motivation to contribute to co-creation activities in a community of users is informed by social exchange theory and relational intrinsic needs. In a community setting, an individual's motivation cannot be led by egocentric drivers as goal divergence would cause the breakdown of the social exchange upon which the co-creation output is dependent. We find motivators then become altruistic in nature, centred on soft extrinsic drivers and relational intrinsic motivators. The value of the co-creation effort appears to be in the process, not its output, and in the social exchange that takes place among a community of like-minded users. It is noteworthy that our results reveal only one motivator is product related. The remainder centre on the social exchange and relational value an individual accrues from co-creating among the community of users. Thus, while Holbrook (2006) demarcated between social and altruistic value, we find from a motivational perspective the two are inherently intertwined and must remain so. Holbrook’s (2006) typology of customer value did not account for those situations in which value is being created in a group. When co-creation takes place within a community of collaborators, social and altruistic motives need to be aligned to keep the group and value for the individual and collective intact. 
Consumers' motivations to engage directly in value co-creation efforts with firms are both opportunity-centred and focused on longer-term product, career and change objectives. These findings are underpinned by the expectation that working closely with the firm will unlock opportunities that affect change in the firm, its products, and the future of the individual involved. These motivations are neither egocentric nor altruistic but rather reflect a hybrid of the circumstances facing the consumer when engaging with a firm. The nature of expectancy would appear fundamental to understanding the conversion of motivation into action and output. Specifically, co-creation output is contingent upon the firm's input as much as the individual's. When instrumentality (likelihood of an outcome occurring) and valence (actual value of the outcome to the individual) of the co-creation effort are high, the consumer is motivated to initiate co-creation activity, as long as the goal is achievable and within his competence. Our results suggest that this activity is further contingent upon compelling involvement in the project by the firm and the consumer's belief that the firm's intentions align with his motivations. Our findings enable researchers to reconsider how value might be optimised across different forms of co-creation and build better studies into the management and performance implications of consumer value co-creation.

In our second contribution, we extend Holbrook's (2006) typology of consumer value into the realm of value (innovation) co-creation efforts. By merging this typology with motivation theories, we seek to illustrate the complexity of customer motivation in value cocreation by synthesizing and reconciling a diverse set of motivational theoretical lenses with Holbrook's (2006) model of consumer value. Our re-construction of Holbrook’s typology is based on relevant motivation theories and map to the results of our qualitative study into consumer value co-creation. This framework indicates that motivations underpinning the value sought from co-creation efforts can be quite different from the forms of value obtained. More importantly, our re-constructed framework and qualitative evidence offer insights into potential causal mechanisms that are drawn from motivation theory and explain the reasons consumers engage in value co-creation that go beyond the rewards they might expect to receive. Other than the assumption that consumers seek satisfying experiences, there is limited evidence in Holbrook’s (2006) assessment of consumer value that explains what motivates the voluntary action to engage in value co-creation. While this explanation might not have been Holbrook's objective, it is important to state that if consumers are not purely rational, utility maximising individuals, then motivation has been a consistently missing link in our understanding of their propensity to engage in value co-creation efforts. Our study contributes to crystallising an understanding of this largely unexplored territory. 
Our third contribution follows directly from this discussion. Our findings show that four motivators appear to operate across the three different forms of value co-creation: fun/interesting, desire for a better product, passion and recognition. However, we contend that these motivators are informed by context and hold different meanings for each type of value creation. For example, the desire for fun and a passion for the product cause a consumer to innovate independent of the firm and these qualities are 'motivating' for their hedonic value. It follows that it is for egocentric reasons that the consumer acts. In terms of the motivation to contribute to joint or community co-creation efforts, however, fun and passion project themselves in more altruistic ways - that is, fun drawn from collaborating with like-minded peers on joint efforts, and passion for the social interaction and learning that takes place within the community. Similarly, the individual hopes this form of co-creation will lead to recognition by his peers of his talents and contributions whereas he seeks something different from direct co-creation with a firm. In this instance the individual seeks recognition in the form of career opportunities that might result from the value the firm places on his capabilities and innovation input. The risk inherent to existing and future empirical treatments of consumer motivation to engage in value co-creation is that devoid of context, motivators could be misinterpreted and meaningful mechanisms that leverage consumer involvement in co-creation may not emerge. Put simply, there is a risk in practice deviating from empirical observations. As such, this work offers a timely contribution to furthering our understanding of engaging consumers in co-creation by providing early indicators of possible stumbling blocks.

Our fourth contribution relates directly to how firms can affect the translation of consumer motivation into end co-creation outputs. In each instance, motivation is constrained by the expectancy that a desired outcome (resembling the motivator) is achievable. To motivate consumers to engage in any form of value co-creation then requires firms to create situations in which consumers are informed of opportunities to co-create innovations in various ways, offering operating environments in which to engage with others in this process, and providing tools that initiate co-creation of innovation. This means that the firm can affect the individual's locus of control in ways that lead him to believe that he has the competency and requisite tools and support to realise innovation outcomes. However, creating an environment of this kind is only one part of the equation. The consumer also collaborates directly with a firm in co-creation activities that are informed by the longer-term objectives of realising better products, seeing change take place in the firm's products, and paving the way for potential for career opportunities. For such motivations to convert into innovation outputs, 
the consumer must believe that the firm is genuine about his involvement. Recent research into consumer cynicism (Chylinski and Chu, 2010) highlights that goal and value incongruence can cause breakdowns in relationships between firms and consumers. Even if relevant resources and tools are offered to consumers to leverage and develop their competencies at value co-creation, few meaningful outputs will emerge if the goals of the firm strike as overtly self-centred. Our work extends theories on consumer motivation to cocreate value by demonstrating the underpinning role of expectancy (theory) in catalysing the process, and provides early indications of the need to empirically consider moderators of the relationship between apparent consumer motivation and co-created outputs. Providing resources to support the consumer's competencies for value co-creation and demonstrating goal congruence will help generate Csikszentmihalyi's (1991) 'flow state' in which the consumer is highly involved with a product and its future.

\section{Limitations and Future Research}

The study findings are constrained by several limitations. A lack of quantitative evaluation prevents generalisability beyond theory. Further, the study did not use multiple samples of consumers such as those engaged and not engaged in the full range of co-creation activities. The new insights offered by this study suggest that empirical work is needed along the continuum of forms of value co-creation to further our understanding of the consumer's motivation to participate in those activities.

\section{References}

Abbott, L. (1955), Quality and Competition, Columbia University Press, New York, NY.

Achrol, R., and Kotler, P. (2006), “The service-dominant logic for marketing: A critique”, in Lusch, R.F., Vargo, S.L. (eds.), The service-dominant logic of marketing: Dialog, debate, and directions, M.E. Sharpe, New York, pp. 320-333.

Bagozzi, R.P. (1975), “Marketing as exchange”, Journal of Marketing, Vol. 39, October, pp. 32-39.

Bandura, A. (1977), "Self-efficacy: Toward a unifying theory of behavioural change”, Psychological Review, Vol. 84, pp. 191-215.

Blazevic, V., and Lievens, A. (2008), "Managing innovation through customer coproduced knowledge in electronic services: An exploratory study", Journal of the Academy of Marketing Science, Vol. 36, pp. 138-151. 
Bryman, A., and Bell, E. (2003), Business Research Methods, Oxford University Press, New York.

Butler, B., Sproull, L., Kiesler, S., and Kraut, R. (2002), “Community effort in online groups: Who does the work and why?”, in Weisband, S., and Atwater, L. (eds.), Leadership at a Distance, John Wiley and Sons, New York.

Chylinski, M., and Chu, A. (2010), "Consumer cynicism: antecedents and consequences", European Journal of Marketing, Vol. 44, No. 6, pp. 796-837.

Cook, S. (2008), “The contribution revolution,” Harvard Business Review, Vol. 86, October, pp. 60-69.

Csikszentmihalyi, M. (1991), Flow: The Psychology of Optimal Experience, Harper and Row, New York.

Curasi, C.F. (2001), “A critical exploration of face-to-face interviewing vs computermediated interviewing”, International Journal of Market Research, Vol. 43, pp. 361-375.

Daugherty, T., Eastin, M.S., and Bright, L. (2008), "Exploring consumer motivations for creating user-generated content”, Journal of Interactive Advertising, Vol. 8, No. 2, pp. 1625.

Deci, E.L. (1992), “Understanding Human Motivation”, in Deci, E.L., Vroom, V.H. (eds.) Management and Motivation, Penguin Books, London.

Deci, E.L., and Ryan, R.M. (1985), Intrinsic Motivation and Self-Determination in Human Behavior. Plenum, London.

Etgar, M.A. (2008), “Descriptive model of the consumer co-production process”, Journal of the Academy of Marketing Science, Vol. 1, pp. 97-108.

Evans, M., Jamal, A., and Foxall, G. (2006), Consumer Behavior, Wiley, West Sussex.

Franke, N., and Shah, S. (2003), "How communities support innovative activities: an exploration of assistance and sharing among end-users”, Research Policy, Vol. 32, pp.157178.

Füller, J. (2006), "Why consumers engage in virtual new product developments initiated by producers”, Advances in Consumer Research, Vol. 33, pp. 639-646.

Füller, J., Bartl, M., Ernst, H., and Muhlbacher, H. (2006), “Community based innovation: How to integrate members of virtual communities into new product development”, Electronic Commerce Research, Vol. 6, No. 1, January, pp. 57-73.

Füller, J., Matzler, K., and Hoppe, M. (2008), “Brand community members as a source of innovation”, Journal of Product Innovation Management, Vol.25, pp. 608-619. 
Gephart, R. (2004), Qualitative research, Academy of Management Journal, Vol. 47, No. 4, pp. 454-62.

Granovetter, M. (1985), “Economic action and social structure: the problem of embeddedness”, American Journal of Sociology, Vol. 91, No. 3, pp. 481-510.

Harhoff, D., Henkel, J. and von Hippel, E. (2003), “Profiting from voluntary information spillovers: how users benefit by freely revealing their innovation”, Research Policy, Vol. 32, pp. 1753-1769.

Hinkle, D. (2011), “Report: Game industry worth \$74bn in 2011”, Available at http://i.joystiq.com/2011/07/05/report-game-industry-worth-74-billion-in-2011/ (Accessed: 02.04.12).

Holbrook, M.B. (2006), “Consumption experience, customer value, and subjective personal introspection: An illustrative photographic essay”, Journal of Business Research, Vol. 59, pp. 714-725.

Jawecki, G. (2008), "Differences in motives to innovate, to engage in innovation activities, and to collaborate with producers", 15th International product development management conference, June 29-July 1, Hamburg, Germany.

Kivetz, R., Urminsky, O., and Zheng, Y. (2006), “The goal-gradient hypothesis resurrected: Purchase acceleration, illusionary goal progress, and customer retention”, Journal of Marketing Research, Vol. 43, No. 1, pp. 39-58.

Kollock, P. (1999), “The economies of online cooperation: Gifts and public goods in cyberspace”, in Smith, M.A., and Kollock, P. (eds.), Communities in cyberspace, Routledge, London.

Kozinets, R.V. (2002), “The field behind the screen: Using netnography for marketing research in online communities”, Journal of Marketing Research, Vol. 39, No. 1, pp. 6172.

Lewin, K. (1951), “Intention, will, and need”, in Rapaport, D., Organization and Pathology of Thought, Columbia University Press, New York.

Locke, K. (2001), Grounded Theory in Management Research, Sage Publications, Thousand Oaks, CA.

Lusch, R.F., and Vargo, S. (2006a), “Service dominant logic: Reactions, reflections and refinements”, Marketing Theory, Vol. 6, pp. 281-288.

Lusch, R.F., and Vargo, S. (2006b). The service-dominant logic of marketing: Dialog, debate, and directions. M.S. Sharpe, New York. 
Mathwick, C., Wiertz, C. and De Ruyter, K. (2008), “Social capital production in a Virtual P3 community,” Journal of Consumer Research, Vol. 34, April, 832-849.

Miles, M.B., and Huberman, M.A. (1994), Qualitative data analysis: a sourcebook of new methods, Sage Publications, Beverly Hills, CA.

Namibisan, S. (2002), “Designing virtual customer environments for new product development: towards a theory”, Academy of Management Review, Vol. 27, No. 3, pp. 392-413.

Payne, A.F., Storbacka, K., and Frow, P. (2008), "Managing the co-creation of value”, Journal of the Academy of Marketing Science, Vol. 36, No. 1, pp. 83-96.

Prahalad, C.K., and Ramaswamy, V. (2004), “Co-creating unique value with customers”, Strategy \& Leadership, Vol. 32, No. 3, pp. 4-9.

Pratt, M. (2009), “For the lack of a boilerplate: Tips on writing up (and reviewing) qualitative research”, Academy of Management Journal, Vol.52, No.5, pp.856-862.

Rotter, J.B. (1966), “Generalized expectancies for internal versus external control of reinforcement”, Psychological Monographs, Vol. 80, No. 1, pp. 1-28.

Shah, S. (2006), "Motivation, governance and the viability of hybrid forms in open source software”, Management Science, Vol. 52, July, pp. 1000-1014.

Szmigin, I., Canning, L., and Reppel, A. (2005), “Online community: enhancing the relationship marketing concept through customer bonding”, International Journal of Service Industry Management, Vol. 16, No. 5, pp. 480-496.

Vargo, S.L., and Lusch, R.F. (2004), "Evolving to a new dominant logic for marketing”, Journal of Marketing, Vol. 68, January, pp. 1-17.

Vroom, V. (1964), Work and Motivation, Jon Wiley and Sons, New York.

Vroom, V.H., and Jago, A.G. (1978), “On the validity of the Vroom-Yetton model”, Journal of Applied Psychology, Vol. 63, pp. 151-162.

Wikstrom, S. (1996), "Value creation by company-consumer interaction”, Journal of Marketing Management, Vol. 12, pp. 359-374.

Xie, C.Y., Bagozzi, R.P., and Troye, S.V (2008), “Trying to prosume: toward a theory of consumers as co-creators of value”, Journal of the Academy of Marketing of Marketing Science, Vol. 36, No. 1, pp. 109-122. 
Figure 1: A Re-imagining of Holbrook's (2006) Consumer Value Typology based on Theoretical Observations from the Motivation Literature

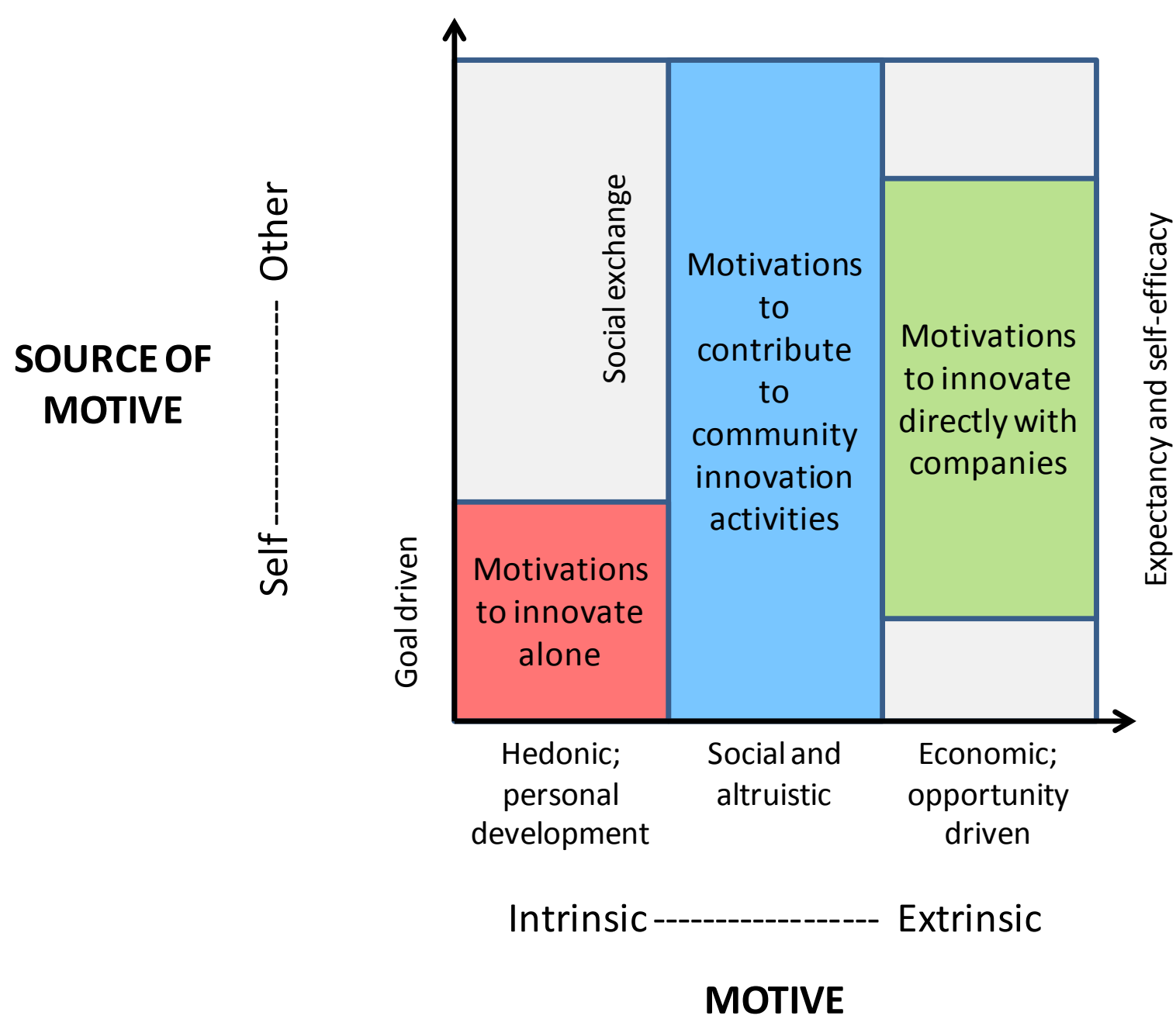


Figure 2: Motivators of Consumer Value Co-creation Efforts

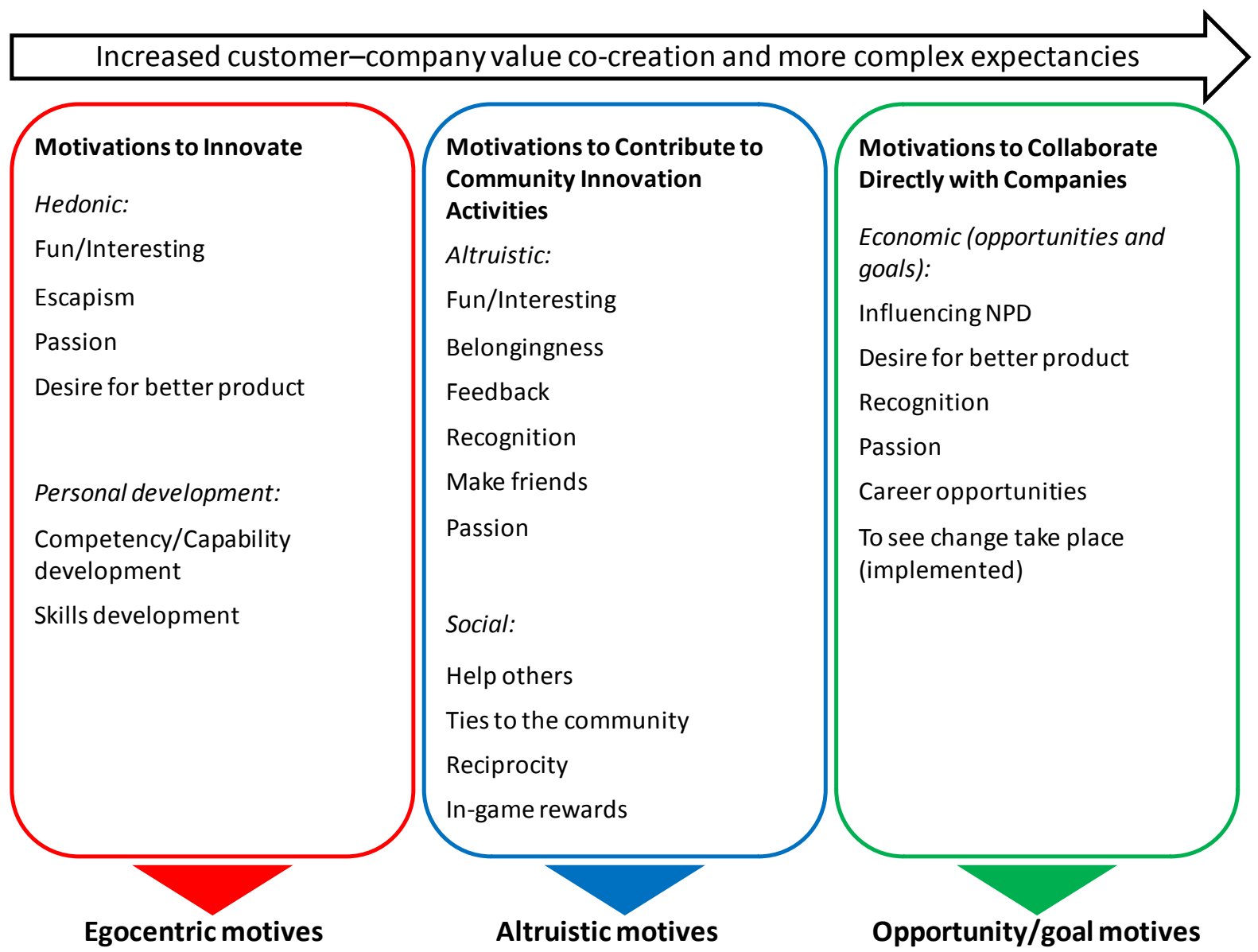


Table 1: Summary of Results

\begin{tabular}{|c|c|c|c|c|}
\hline $\begin{array}{l}\text { Innovation } \\
\text { Activity }\end{array}$ & Key Terms & Evidence in the data & $\begin{array}{l}\text { Evidence associated } \\
\text { with }\end{array}$ & $\begin{array}{l}\text { Emerging } \\
\text { dimensions and } \\
\text { points of } \\
\text { discussion } \\
\end{array}$ \\
\hline $\begin{array}{l}\text { Joint } \\
\text { Innovation }\end{array}$ & $\begin{array}{l}\text { Extrinsic } \\
\text { Motivation }\end{array}$ & $\begin{array}{l}\text { "The urge to share expertise comes to mind. When you have a } \\
\text { little knowledge on the subject, you would want to share it with } \\
\text { others to not only help others, but improve your own skills as } \\
\text { well. When I see that I actually have some understanding of the } \\
\text { subject matter at hand, I would like to put in my two cents and } \\
\text { see how my opinion weighs against others. Even then, I can } \\
\text { still learn a thing or two from others offering their expertise on }\end{array}$ & $\begin{array}{l}\text { Motivation drawn from } \\
\text { factors outside the } \\
\text { individual. }\end{array}$ & $\begin{array}{l}\text { Egocentric } \\
\text { motives give } \\
\text { way to altruistic, } \\
\text { social and } \\
\text { community } \\
\text { driven motives } \\
\text { oriented around }\end{array}$ \\
\hline
\end{tabular}




\begin{tabular}{|c|c|c|c|c|}
\hline & $\begin{array}{l}\text { Social } \\
\text { Exchange }\end{array}$ & $\begin{array}{l}\text { the matter at hand. Not only would I like to be considered } \\
\text { helpful, but I just want to learn as much as anyone else. I want } \\
\text { to have some fun.” } \\
\text { "I wanted to connect with other players. [...] it makes for a } \\
\text { stronger community and its fun. It's fun talking about different } \\
\text { strategies and game changes with other people. It’s a good } \\
\text { learning experience.” } \\
\text { "Firstly, I have gotten a lot from the community and it is only } \\
\text { polite to give back. [...] I think the concept of reciprocation is a } \\
\text { driving force behind the sharing of content with the } \\
\text { community. If you spend any time here you will most likely get } \\
\text { something from it and you will be more likely to give } \\
\text { something back. If you don't give back, then people are going } \\
\text { to be less likely to help you in the future”. “Online } \\
\text { communities only exist as long as people contribute to them } \\
\text { and once people are only taking and not giving, the community } \\
\text { will wither away to nothing but guests and lurkers.” } \\
\text { “It provides a very nice emotional outlet as I am able to } \\
\text { achieve a level of recognition for my efforts. [...] It has become } \\
\text { simply a passing along of what I have learned, and developing } \\
\text { ideas to improve upon the status-quo. Share it [user-generated } \\
\text { content] because someone ought to enjoy what I have made, } \\
\text { and I personally don’t get much time to play (would rather mod } \\
\text { when I have the free time). [...] gaining input on my work isn’t } \\
\text { really a motivation, just letting others enjoy it and gaining } \\
\text { compliments/acknowledgement, pretty much in that order.” }\end{array}$ & $\begin{array}{l}\text { Sharing ideas and } \\
\text { developing user- } \\
\text { generated content must } \\
\text { be rewarding to each } \\
\text { participant in } \\
\text { community. } \\
\text { Participation connects } \\
\text { an innovator with their } \\
\text { peer group and helps } \\
\text { develop strong ties. }\end{array}$ & $\begin{array}{l}\text { the benefits } \\
\text { drawn from } \\
\text { close interaction } \\
\text { with peers } \\
\text { Sharing } \\
\text { information and } \\
\text { ideas are } \\
\text { subjected to peer } \\
\text { reviews, and } \\
\text { appear relevant } \\
\text { to the } \\
\text { motivations of } \\
\text { the individual } \\
\text { Social exchange }\end{array}$ \\
\hline Direct & Extrinsic & "Constructive criticism is the best way to ensure that the game & Motives are driven by & Motives appear \\
\hline
\end{tabular}




\begin{tabular}{|c|c|c|c|c|}
\hline $\begin{array}{l}\text { Collaboration } \\
\text { with the Firm }\end{array}$ & $\begin{array}{l}\begin{array}{l}\text { Self/career } \\
\text { advancement }\end{array} \\
\text { Goals } \\
\text { Recognition } \\
\text { Shaping } \\
\text { future } \\
\text { products }\end{array}$ & $\begin{array}{l}\text { is moving in the right direction. [...] While the developers } \\
\text { [game publishers] typically make up their own ideas, if they're } \\
\text { going in the wrong direction, it’s great to be able to tell them } \\
\text { what they could be doing instead, in order to keep the game } \\
\text { afloat. [...] I intend to be a game developer in the future (or at } \\
\text { least in the field of game development,) and by sharing my } \\
\text { ideas I would be able to see how the community in general } \\
\text { would like it if I were to use it in one of my own games.” } \\
\text { "Maybe if enough people come forward the dev's will do } \\
\text { something about it. [...] If they liked my content well enough, } \\
\text { they may feature it. [...] Mainly I benefit by receiving } \\
\text { recognition, but who knows there may be other opportunities in } \\
\text { the future.” } \\
\text { "On this site we do see company reps and testers in relative } \\
\text { abundance. Sharing ideas sometimes results in actual code } \\
\text { rewrites improving the value of the game, making it even more } \\
\text { addictive. [...] Talking to the company, even indirectly, has } \\
\text { resulted in positive developments making it seem foolish to me } \\
\text { to shy away from that.” }\end{array}$ & $\begin{array}{l}\text { The motivation to } \\
\text { accomplish personal } \\
\text { goals (e.g., career } \\
\text { goals) through } \\
\text { innovation activities. } \\
\text { The opportunity to be } \\
\text { involved and } \\
\text { recognised for shaping } \\
\text { the next generation of } \\
\text { games. }\end{array}$ & $\begin{array}{l}\text { to revolve } \\
\text { around the } \\
\text { Holbrookian } \\
\text { notion of } \\
\text { 'economic' } \\
\text { value } \\
\text { Economic value } \\
\text { represents } \\
\text { motives aligned } \\
\text { around } \\
\text { opportunities for } \\
\text { career } \\
\text { advancement } \\
\text { and more } \\
\text { closely-aligned } \\
\text { goals (and } \\
\text { rewards) } \\
\text { between the } \\
\text { customer and the } \\
\text { firm }\end{array}$ \\
\hline
\end{tabular}

\footnotetext{
${ }^{[1]}$ User-generated game content are normally created with the help of software provided by either the game publisher or third-party programming/multimedia software providers that allow users to modify features of the game. As such, every form of co-creation we study here has some link back to the firm that owns the initial product. To an extent, the scope of users to modify a game will depend on how customizable the game publisher has made its game code (e.g., the 'engine' it is built on) or whether the code is built on an 'open' engine. The level of expertise needed to use any given software/toolkit differs.
} 